\title{
iPhones for eye surgeons
}

Eye (2012) 26, 343-354; doi:10.1038/eye.2012.6

\section{Introduction}

In a survey of mobile phone ownership, $99 \%$ of health professionals own a mobile phone, with $81 \%$ of these being a smartphone. ${ }^{1}$ The most popular smartphone currently being the Apple iPhone. Mobile phones and the internet have arguably been two of the most important developments in recent decades and the development of smartphones has combined these to allow many handheld capabilities beyond basic voice and text communication including advanced computing, digital photography, and geo-positioning.

Such devices are popular because of their high quality graphical user interfaces and intuitive control. The felt necessity by most adults to carry a mobile phone device with them at all times has meant that the increased capabilities of smartphones have come at no extra pocket space and in many cases for medical professionals has replaced the trusted handbook that once sat there.

Ophthalmologists are notorious for their interest in technology and gadgetry and so it comes as no surprise that the use of smartphones such as iPhones by ophthalmologists is wide spread.

For the purpose of this article we will look at the currently available applications and uses for an iPhone by an ophthalmologist (other platforms exist that provide the same or similar smartphone applications).

The potential functions of the ophthalmology related iPhone applications currently available can be divided into the following broad categories:

(1) Patient assessment tools

(2) Patient education/visual aids

(3) Health care profession education and reference

(4) Patient records/administrative tools and

(5) Multiple functionalities.
A Bastawrous ${ }^{1}, \mathrm{RC}$ Cheeseman² and A Kumar ${ }^{2}$

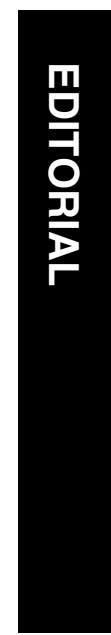

\section{Patient assessment tools}

Comprehensive assessment and examination of patients with ocular problems require the use of an array of diagnostic tools. In the ophthalmology, clinical setting of these tests are readily available but in the accident and emergency setting with an exiguous 'Eye Examination Room' or during emergency call outs these tools can be available at a touch of a button. There are several applications, which can assess visual acuity using either the familiar Snellen visual acuity test or modern interactive visual acuity tests. Some of the applications have tests for colour vision, astigmatism, pupil size, oculomotor reflexes, and red desaturation (see Table 1).

\section{Patient education/visual aids}

Patients will often ask questions in clinic about their condition; What is it? Why do I have it? How is it treated? Some clinics even employ specialist nurses to undertake patient counselling activities, such as with macular degeneration and glaucoma. Providing patients with narrated video content can help answer all these questions in a way that discussion alone cannot. The portability of the iPhone makes this ideal for providing information to patients in clinic, but for the more technologically confident patient, they can download the application to their own iPhone device and review the information at their leisure, and show it to friends and relatives, relieving them of the burden of translating the sometimes complicated explanations of their ophthalmological condition (see Table 2).

\section{Health care profession education and reference}

Learning and professional development for health care professionals and students is changing since the introduction of the smartphone. ${ }^{2}$ With the limited number of hours available to catch up on the latest results from
${ }^{1}$ Clinical Research Fellow in International Eye Health, International Centre for Eye Health, London School of Hygiene and Tropical Medicine, London, UK

${ }^{2}$ St Paul's Eye Hospital, Royal Liverpool University Hospital, Liverpool, UK

Correspondence: A Bastawrous, Clinical Research Fellow in International Eye Health, International Centre for Eye Health,

London School of Hygiene and Tropical Medicine, Keppel Street, London WC1E 7HT, UK

Tel: + 44 (0)20 76368636 ; Fax: + 44 (0)20 74365389 E-mail: andrew.bastawrous@ gmail.com 
Table 1 List of iPhone applications, which can be used by patients to test basic visual acuity and health care professionals to perform more detailed assessments of visual function

\begin{tabular}{|c|c|c|c|c|}
\hline $\begin{array}{l}\text { Application name } \\
\text { (Developer) }\end{array}$ & Size & Customer rating & Cost & Description \\
\hline Macula tester & $0.3 \mathrm{MB}$ & No ratings & $£ 1.49$ & $\begin{array}{l}\text { An interactive amsler grid test for patients, which can be used to } \\
\text { record areas of distortion. 'Push notification' reminds patients to } \\
\text { conduct tests regularly. }\end{array}$ \\
\hline
\end{tabular}

(Sabina techonology LLP)

$\begin{array}{ll}\text { Amsler chart lite and } & 851 \mathrm{~KB} \\ \text { amsler chart } & 206 \mathrm{~KB}\end{array}$

(1)

(Park house systems)

Amsler vision

1.1 MB No ratings

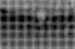

(Maturi consulting LLC)

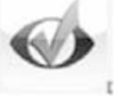

Vision check

(Allergan Inc.)

Check my vision

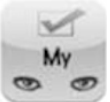

(Scott kehrberg)

Vision

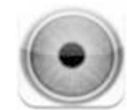

(Dmitriy glebenok)

At home eye exam

19)

(McApps)

A simple eye exam

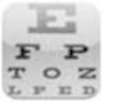

(McApps)
2.2 MB No ratings

$0.1 \mathrm{MB}$ No ratings

22.3 MB 3 Stars (27 reviewers)

$1.0 \mathrm{MB} 2$ Stars (8 reviewers)

$1.1 \mathrm{MB}$ No ratings
Free This application allows patients diagnosed with a macula disease to $£ 0.69$ monitor any change in their vision. Health care professionals can also use it to check patients for potential macular abnormalities.

$£ 1.49$ Personal amsler and visual acuity testing application.

Free Three vision test

- Tumbling ' $\mathrm{E}$ ' test

- Tumbling shape test and

- The amsler test

Plus information on glaucoma, cataract, and diabetic retinopathy.

$£ 0.69$ Snellen chart and amsler grid to check vision.

The application also allows user to store their spectacle and contact lens prescription.

Free Visual acuity, ishihara colour test, astigmatism test, retinal functional test, visual field test, and face memory test. Also included in this application is a section on entertainment and fun, eye exercises and practical information, and help.

$£ 0.69$ Visual acuity test, amsler test, and colour-blind tests.

$£ 0.69$ Series of eyesight and vision exams. 
Table 1 (Continued)

\begin{tabular}{|c|c|c|c|c|}
\hline $\begin{array}{l}\text { Application name } \\
\text { (Developer) }\end{array}$ & Size & Customer rating & Cost & Description \\
\hline $\begin{array}{l}\text { iSight test } \\
\qquad \begin{array}{c}0 \\
0 ல\end{array}\end{array}$ & $1.3 \mathrm{MB}$ & $\begin{array}{l}5 \text { Stars } \\
\text { (8 reviewers) }\end{array}$ & $£ 8.99$ & Vision testing including \\
\hline \multicolumn{5}{|l|}{ (Kay pictures Ltd) } \\
\hline (3ision test & $7.7 \mathrm{MB}$ & $\begin{array}{l}4 \text { Stars } \\
\text { (84 reviewers) }\end{array}$ & Free & $\begin{array}{l}\text { Visual acuity test, } \\
\text { astigmatism test, } \\
\text { duochrome test, } \\
\text { colour test, } \\
\text { far field vision test, } \\
\text { optician finder, } \\
\text { eye quiz, } \\
\text { eye advice, and facts. }\end{array}$ \\
\hline Vision! test & $584 \mathrm{~KB}$ & No ratings & $£ 0.69$ & Simple vision test. \\
\hline
\end{tabular}

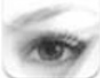

(Wow systems

informatica Lda.)

Eye test pro

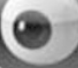

(Thomas mitchell)

EyeXam

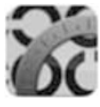

(Global eye ventures

LLC)

Eye test

(6)

(cateater LLC)

Eye Exam

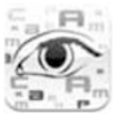

(Nuno carvalho

entertainment)

Senses-What you see?
6.2 MB 5 Stars

(18 reviewers)

18.3MB 3 and fraction 12; Stars (16 reviewers)
$£ 0.69$ A comprehensive application for eye care professionals, which includes Snellen chart, individual testing letters, contrast sensitivity testing, duochrome tests, cross cylinder test, number plate assessment test, reading test, ishihara test, and amsler chart distance fixation images for ophthalmoscopy.

Free Includes tests for visual acuity, colour perception, astigmatism, eye dominance, and links to obtain more information.

$£ 0.69$ Tests for visual acuity, colour blindness, astigmatism, duochrome, and macular degeneration.
$6.1 \mathrm{MB}$ No ratings

$£ 1.49$ Self tests for near and distance visual acuity.

$626 \mathrm{~KB}$ No ratings

Free Designed to conduct vision screening, mainly in children and youth. The examination uses colour vision and contrast differentiation tests.

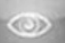

(Baltronic) 
Table 1 (Continued)

\begin{tabular}{lllll}
\hline $\begin{array}{l}\text { Application name } \\
\text { (Developer) }\end{array}$ & Size & Customer rating & Cost Description \\
\hline $\begin{array}{l}\text { Opt Eyecheck-eye } \\
\text { examinations/colour } \\
\text { baind }\end{array}$ & $2.1 \mathrm{MB}$ & No ratings & $£ 0.69 \begin{array}{l}\text { Includes a near vision, colour vision, amsler grid, and contrast } \\
\text { sensitivity checks. }\end{array}$
\end{tabular}
blind...

(O)

(Cygnet infotech LLC)

Visual acuity

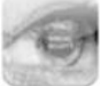

(Kybervision consulting, R\&D)

Fast acuity

\section{(6)}

(Kybervision consulting, R\&D)

HOTV acuity

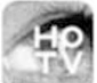

(Kybervision consulting, R\&D)

Sloan acuity

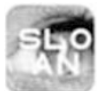

(Kybervision consulting, R\&D)

Eye Chart HD

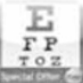

(Dok LLC)

Colour vision test free

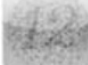

(Meeni techno)

Colour blind test

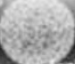

(Tomato Co. Ltd.)
$2.0 \mathrm{MB}$ No ratings

2.6 MB No ratings

$582 \mathrm{~KB}$ No ratings

$570 \mathrm{~KB}$ No ratings

$582 \mathrm{~KB}$ No ratings

3.0 MB $2 \frac{1}{2}$ Star

(43 reviewers)

$0.6 \mathrm{MB} 3$ Stars (14556 reviewers)
$£ 6.99$ Visual acuity test for health care professionals using the logMAR acuity. For the non-health care professionals they recommend the fast acuity, hotv acuity, or the solan acuity.

$£ 1.99$ Interactive eye chart for the non-professional.

$£ 0.69$ For pre-school children and illiterate people.
Free Snellen and Tumbling E chart.

Free Colour vision tests.

Free Check if you are colour blind 
Table 1 (Continued)

\begin{tabular}{lcll}
\hline $\begin{array}{l}\text { Application name } \\
\text { (Developer) }\end{array}$ & Size & Customer rating & Cost Description \\
\hline Colour vision test & $4.6 \mathrm{MB}$ & No ratings & $£ 0.69$ Contains 16 colour plates.
\end{tabular}

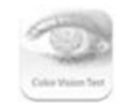

(Rila software)

Pseudochromatic

Colour test

1.2 MB $3 \frac{1}{2}$ Stars (502 reviewers)

$105 \mathrm{~KB}$ No ratings

$£ 0.69$ Simple Application to estimate pupil size.

$£ 1.49$ Tests include:

- Ishihara plate

- OKN strip

- Pupil Chart

- Red desaturation

- Visual acuity test.

$£ 1.49$ Features: Snellen charts and Illiterate E chart can be used as a screening tool.

generator

$157 \mathrm{~KB}$ No ratings

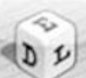

(Dok LLC)

$\mathrm{OKN}+$

$162 \mathrm{~KB}$ No ratings

$£ 1.99 \mathrm{OKN}$ test and red desaturation test.

(Touch Diagnostics, LLC)

Optodrum

$278 \mathrm{~KB}$ No ratings

III

(Linsay associates, LLC)

Visual acuity converter

$892 \mathrm{~KB}$ No ratings

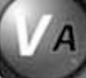

(EB Eye limited)
$£ 1.99$ Replacement for the OKN drums, different patterns with adjustable width and speed.

$£ 2.99$ Converts between the commonly used visual acuity notations, calculates astigmatism,

biometry,

optical formulas,

toric IOL calculator, and

refraction converter. 
Table 2 List of iPhone applications, which can be used by healthcare professionals or patients for education about ophthalmic conditions and treatments, and applications that can be used as visual aids

\begin{tabular}{lllll}
\hline $\begin{array}{l}\text { Application name } \\
\text { (Developer) }\end{array}$ & Size & $\begin{array}{l}\text { Customer } \\
\text { rating }\end{array}$ & Cost & Description \\
\hline Eye Model & $4.2 \mathrm{MB}$ & $\begin{array}{l}\text { 2 Stars } \\
(5 \text { reviewers })\end{array}$ & $£ 0.69$ & $\begin{array}{l}\text { Interactive model eye, allowing different viewing angles and } \\
\text { different layers. Good for demonstrating eye anatomy to } \\
\text { patients while explaining their problems. }\end{array}$ \\
& & & &
\end{tabular}

(Evandro Souza)

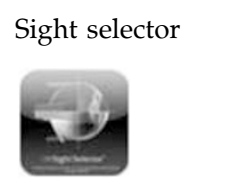

(Patient education concepts Inc.)

Eye health

$3.4 \mathrm{MB}$

Lite $=33.6 \mathrm{MB}$
Premium $=602 \mathrm{MB}$

No ratings

free

premium

$£ 324.99$

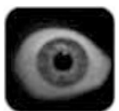

(Stroika)

Miniatlas glaucoma

$35.1 \mathrm{MB}$

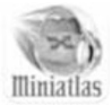

(ec-europe)

Mini atlas age-

related macular

degeneration

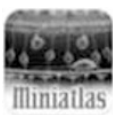

(ec-europe)

Eye patients mobile $7.3 \mathrm{MB}$

free

$36.4 \mathrm{MB}$

No ratings

$£ 4.99$

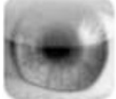

(George Kong

Softwares)

Eye Snapi

$0.5 \mathrm{MB}$

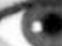

(MobileDx)
No ratings Free

No ratings

Free (with additional charges)
A reference for students and patients alike, this application describes common conditions, their causes, and illustrates them with pictures and diagrams. Also contains an illustrated glossary.

Free version of application built into add-on modules that can be bought separately. Each module helps to educate patients about a particular condition or procedure ranging from laser vision correction to macular degeneration.

This application helps you to explain to your patient the diagnosis of glaucoma, its management, and its effects through the use of clear images and diagrams.

A similar patient education application as the mini atlas glaucoma.

This application can be used by patients to maintain a record of their own ophthalmic history, including medication instructions and IOP measurements (which can be presented in graphical form). It can also be used by doctors as a surgical/audit log.
This free application allows patients to make measurements such as visual acuity and amsler charts, as well as take photographs, which can be emailed to a doctor for assessment. However, these emails are charged at $\$ 0.99$ each in America and it is not known whether UK users are charged a commensurate rate. 
Table 2 (Continued)

\begin{tabular}{lllll}
\hline $\begin{array}{l}\text { Application name } \\
\text { (Developer) }\end{array}$ & Size & $\begin{array}{l}\text { Customer } \\
\text { rating }\end{array}$ & Cost & Description \\
\hline Eye lifestyles & $62.0 \mathrm{MB}$ & No ratings $£ 399.99$ & $\begin{array}{l}\text { This patient education application helps to educate patients } \\
\text { on advanced lifestyle vision and cataract surgery options. } \\
\text { The cost of the application includes additional support, } \\
\text { integrating the material into your pre-operative patient } \\
\text { education process. }\end{array}$
\end{tabular}

(Patient education

concepts Inc.)

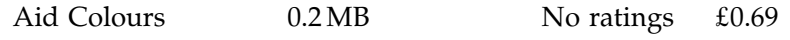

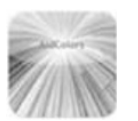

(Tilenus consultores

S.L)

Colour detect

$0.5 \mathrm{MB}$

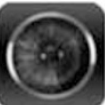

(sunset software

LLC)
Colour-blind patients can use this application to identify the colour of a surface in front of the camera of the iPhone. The application will then return the written name of the colour of the surface tested. landmark studies this information can be distributed quickly and effectively with the use of modern technology. Applications that offer reference material may eliminate the need to carry heavy 'text books' and indeed provide essential reading material on the 'go'. Some of the applications provide videos and colour atlas quizzes, which will be useful for training and examination preparations. Others help plan refractive and intraocular lens calculation for cataract surgery and analysis of postoperative results, such as plots of surgical induced astigmatism (see Table 3).

\section{Patient records/administrative tools}

There is a demand for greater productivity and so being able to access patient information remotely and securely is paramount. Some products are flexible enough to allow information to be passed from a remote location, such as an optometrist, for advice to be fed back about management and referral in true telemedicine fashion. A number of solutions exist for this problem to suit every budget (see Tables 4 and 5).

\section{Future hardware and possibilities}

As well as downloadable software applications, there are in development several additional hardware tools. These include an autorefractor (NETRA), cataract grader (CATRA) and ultrasound scanner. The NETRA autorefractor has in two separate pilot studies demonstrated good accuracy as compared with subjective refraction (mean difference in spherical equivalent of $0.18 \mathrm{D}^{3}$ and $0.24 \mathrm{D}^{4}$ respectively), the same group who developed the NETRA at the Massachusetts Institute of Technology are developing the CATRA for self-grading of cataracts. MobiUS have created an FDA approved smartphone ultrasound imaging device, which uses a hand held wand and the smartphone as a portable imaging system. With small adaptations this could be suitable for ocular ultrasound examination.

Imaging of the eye via a slit lamp has been described previously, ${ }^{5}$ with recently developed adaptors (Keeler Apple iPhone 4 PSL-imaging adapter, London, UK) now on the market. Imaging the fundus using an iPhone, indirect lens and ophthalmoscope ${ }^{6}$ and an alternative technique without the need for the ophthalmoscope have been described. ${ }^{7}$ iPhones have been used in teleophthalmology retinopathy of prematurity outreaches in India with success, ${ }^{8}$ but to date have required large imaging devices such as the RetCam. With future developments it is likely that an attachable fundus camera will fit directly on to a smartphone with wide field images created by existing photo-stitching packages and making it a truly portable fundus camera. 
Table 3 List of iPhone apps, which can be used by health care professionals for reference and personal development

\begin{tabular}{lllll}
\hline Application name (Developer) & Size & $\begin{array}{l}\text { Customer } \\
\text { rating }\end{array}$ & Cost & Description \\
\hline Minor eye lid surgery & $372 \mathrm{MB}$ & No ratings & $£ 0.69$ & Contains basic procedures as videos.
\end{tabular}
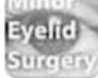

(Innovation technologies)
Ophthalmology

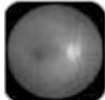

(Faribu.com)

The Wills eye manual

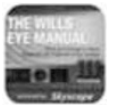

(Skyscape)

OSN supersite

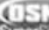

ossint

(The Wyanoke Group)

Ophthalmology glossary

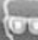

(deep powder software)

Retina atlas

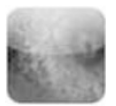

(medina systems)

iEye retina

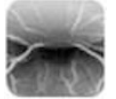

10.2MB No ratings

(Isha innovations)

Academy2GO-CIBA vision academy for eye care excellence
31.7 MB No ratings

$273 \mathrm{~KB} \quad 3$ and fraction 12; Stars

(5 reviewers)

$1.5 \mathrm{MB}$ No ratings

$570 \mathrm{MB}$ No ratings

$£ 0.69$

Glossary.
$£ 54.99$

Free
Interactive digital atlas of retinal disease.
$461 \mathrm{MB} 2$ Stars (15 reviewers)
Ocular surgery news, surgical videos, and blogs meeting highlights from around the world.

Essential for clinic and emergency use with severa new sections and results from new studies.

Basic education, and general ophthalmology information. 
Table 3 (Continued)

\begin{tabular}{lclcl}
\hline Application name (Developer) & Size & $\begin{array}{l}\text { Customer } \\
\text { rating }\end{array}$ & Cost & Description \\
\hline EyeDock & $3.3 \mathrm{MB}$ & $\begin{array}{l}1 \text { Star } \\
(14 \text { reviewers })\end{array}$ & $\begin{array}{c}\text { Free } \\
\text { (membership } \\
\text { required })\end{array}$ & Contact lens power calculator. \\
eYe & & &
\end{tabular}

(Todd M Zarwell OD)

OHT Calc

$0.4 \mathrm{MB}$ No ratings

$0.9 \mathrm{MB}$ No ratings

Optics Clinical Calculator

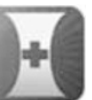

(Eva Schoenberg)

PAK

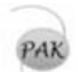

(El Patagonauta)

Toric Lab

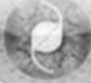

(Evandro Souza)

LRI Calc

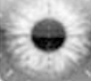

(Evandro Souza)

Eye Pro 2011

1.2 MB No ratings

1.0 MB No ratings

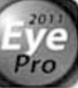

(EB Eye limited)
1.4MB No ratings

2.1MB No ratings

$£ 0.69$

Pre-optical planning of limbal-relaxing incisions.
$£ 0.69$

Glaucoma risk calculator based on OHTS and EGPS studies.

$£ 2.99 \quad$ Refractive calculators.
Free $\quad$ Post myopic refractive surgery IOL Calculator and Calculator of safety parameters for LASIK.
Astig PLOT

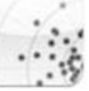

(EB eye linited)
$£ 2.99$ Calculate IOL power for cataract/refractive surgery.

$£ 18.99$ Features for anterior segment surgeons, biometry

visual acuity Converter, and astigmatism plots.

$£ 6.99$
Statistical analysis of astigmatism in a group of eyes. Part of eye PRO 2011 application. 
Table 3 (Continued)

\begin{tabular}{lllll}
\hline Application name (Developer) & Size & $\begin{array}{l}\text { Customer } \\
\text { rating }\end{array}$ & Cost & Description \\
\hline Eye vectors & $4.7 \mathrm{MB}$ & No ratings & $£ 1.99$ & $\begin{array}{l}\text { Vector analysis } \\
\text { Toric IOLs or LRIs. }\end{array}$ \\
$\begin{array}{l}\text { (Evandro Souza) } \\
\text { PachyIOP }\end{array}$ & $0.2 \mathrm{MB}$ & No ratings & $£ 1.49$ & IOP conversion based on pachimetry.
\end{tabular}

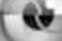

(Farotech)

LASIK clinical calculator

$0.5 \mathrm{MB} \quad$ No ratings

$£ 2.99$

Calcualtor for LASIK refractive surgery.

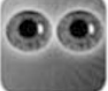

(Evan schoenberg)

Open Ophthalmology-Podcast Application

4.2MB No ratings

$£ 6.99$

Ophthalmology lectures as podcasts.

$0.1 \mathrm{MB} \quad$ No ratings

$£ 2.49$

Calculate spherical equivalent and switch between positive and negative cyl.

(diffraction limited design LLC)

ODwire.org

\section{OD}

(End of time studios LLC)

As seen from here-Podcast Application
$\left.A^{\prime \prime)}\right)$

From Heen

(Wizzard Media)
3.7MB No ratings

$4.9 \mathrm{MB}$ No ratings

Free

$£ 6.99$
Social network for eye care professionals, trade ideas, buy equipment, and much more. Open to optometrists, ophthalmologists, licensed opticians, and students.

Podcast of interviews of recent peer-reviewed publications.

Host Josh Young, MD

American society of cataract and refractive surgery. 
Table 4 List of iPhone applications that facilitate patient medical record/imaging management and administration

\begin{tabular}{|c|c|c|c|c|}
\hline $\begin{array}{l}\text { Application name } \\
\text { (Developer) }\end{array}$ & Size & $\begin{array}{l}\text { Customer } \\
\text { rating }\end{array}$ & Cost & Description \\
\hline $\begin{array}{l}\text { OCT browser } \\
\text { for iPhone }\end{array}$ & $33.4 \mathrm{MB}$ & $\begin{array}{l}\text { No } \\
\text { ratings }\end{array}$ & Free & $\begin{array}{l}\text { This application allows you to carry OCT images on your iphone } \\
\text { using dedicated OCT browser software. Images are compressed, } \\
\text { and owing to the slower speeds of older iphone models, works } \\
\text { best on iphone } 3 \mathrm{GS} \text { and } 4 \text {. }\end{array}$ \\
\hline
\end{tabular}

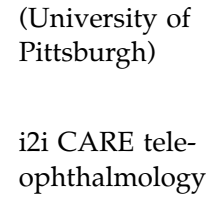

(University of

Pittsburgh)

i2i CARE tele-
ophthalmology

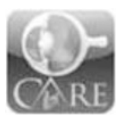

(i2i telesolutions)

Eye route mobile
18.6 MB No ratings
$£ 13.99$ (although additional setup costs anticipated)

Images can be taken with a mobile or stationary ophthalmic camera and uploaded to a TelePACS server. These images can then be accessed through this application locally or remotely. Images can be compared with previous ones.
Another imaging electronic medical record solution, designed to integrate with other Topcon equipment, allowing remote access and reporting of patient images.

Table 5 Applications with multiple functions

\begin{tabular}{|c|c|c|c|c|}
\hline Application name (Developer) & Size & Customer rating & Cost & Description \\
\hline $\begin{array}{l}\text { Eye handbook } \\
\text { EHB }\end{array}$ & $11.7 \mathrm{MB}$ & $\begin{array}{l}3 \text { Stars } \\
\text { (196 reviewers) }\end{array}$ & Free & $\begin{array}{l}\text { Many features including reference, links to journals, } \\
\text { eye atlas, tests, recording patient details, collaboration } \\
\text { with the American Academy of ophthalmology and } \\
\text { much more. }\end{array}$ \\
\hline
\end{tabular}

(Cloud nine development LLC)

\begin{tabular}{|c|c|c|c|c|}
\hline iChart 2000 & $41.6 \mathrm{MB}$ & $\begin{array}{l}3 \text { and fraction } \\
12 ; \text { Stars } \\
(10 \text { reviewers })\end{array}$ & $£ 15.99$ & $\begin{array}{l}\text { Tools include: } \\
\text { near vision and } 3 \mathrm{~m} \text { assessment, } \\
\text { patient information-images and video to help explain }\end{array}$ \\
\hline $\begin{array}{|ll|} & 0 \\
0 & 0\end{array}$ & & & & $\begin{array}{l}\text { conditions to patients, } \\
\text { tool kit to calculate eye-related calculations. }\end{array}$ \\
\hline
\end{tabular}

(Potters bar eye care limited) 


\section{Concluding remarks}

Rapidly advancing technology has literally put knowledge in the palm of our hands. The possibilities for investigations, teaching, information sharing, research, collaboration, and ultimately improved patient care are endless.

\section{References}

1 Retrieved from: http://www.d4.org.uk/research/surveymobile-phone-use-health-professionals-UK.pdf (accessed on 12.07.2011)

2 Retrieved from: http://www.bbc.co.uk/news/education11427317 (accessed on 03.08.2011).

3 Pesala V. Comparison of a Novel Cell Phone-Based Refraction Technique (NETRA) with Objective Clinical Retinoscopy. Presented at ARVO 2011 (available at http:// www.abstractsonline.com/plan/ViewAbstract.aspx?mID
$=2684 \& s K e y=0 b 899 b 6 c-74 f 0-491 c-9 a e e-a 318 c 404505 b \& c K e y$ $=51454242-89 \mathrm{c} 0-499 \mathrm{c}-83 \mathrm{ff}-\mathrm{b} 981 \mathrm{caf0b} 71 \mathrm{a} \& \mathrm{mKey}=\% 7 \mathrm{~B} 6 \mathrm{~F} 224 \mathrm{~A} 2 \mathrm{D}-$ AF6A-4533-8BBB-6A8D7B26EDB3\%7D).

4 Bastawrous A. Validation of Near Eye Tool for Refractive Assessment (NETRA) - Pilot Study. Presented at NEOS 2011 (available at http://www.neos.org.uk/NoE_Programme_spring_2011.pdf).

5 Barsam A, Bhogal M, Morris S, Little B. Anterior segment slitlamp photography using the iPhone. J Cataract Refract Surg 2010; 36(7): 1240-1241.

6 Lord RK, Shah VA, San Filippo AN, Krishna R. Novel uses of smartphones in ophthalmology. Ophthalmology 2010; 117(6): 1274.e3-1274.e3.

7 Bastawrous A. Smartphone Fundoscopy. Accepted to Ophthalmology 2011; July 2011 (in press).

8 Kreatsoulas J. Progress in ROP management through tele-ophthalmology. Retina Today 2010; November/December: 18-20. 